\title{
Spiritually and mental health among normal and chronic disease group
}

Sodhi, Renu

Department of Applied Psychology, Guru Jambheshwar University of Science \& Technology, Hisar-Haryana, India (rn.sodhi@gmail.com)

Dr. Manju

Department of Applied Psychology, Guru Jambheshwar University of Science \& Technology, Hisar-Haryana, India (dr_manju2007@yahoo.co.in)

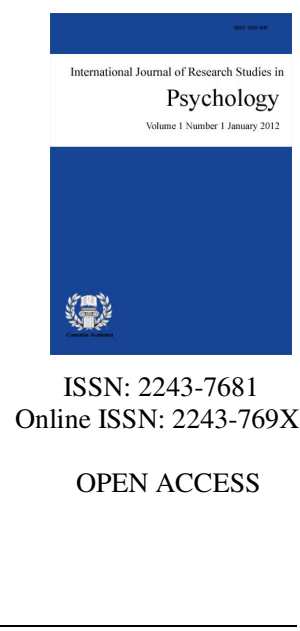

Received: 29 April 2012

\section{Abstract}

The current study investigates the impact of spirituality on mental health among normal healthy individuals and chronic disease group. This study is based on primary as well as secondary data that has been collected from the various sources. Sample size of the study is 100 respondents (50 normal healthy individuals, 50 chronic disease group individuals). Spirituality assessment Inventory (SAI) and General Health Questionnaire (GHQ) were used for the purpose of data collection. In statistical tools Pearson correlation and t-test has been applied. The major findings of the study shows that spirituality is significantly correlated with mental health and normal healthy individuals have higher spirituality and better mental health in comparison to chronic disease group.

Keywords: spirituality; mental health; normal healthy individuals; chronic diseases group 


\section{Spiritually and mental health among normal and chronic disease group}

\section{Introduction}

Body and mind are inseparable; a sound mind in a sound body and vice-versa; Health of these two is interlocked. For healthy and meaningful life balance between these two is not only a sufficient but also a necessary condition. WHO (1958) defined health not merely as the absence of illness but as physical, mental and social well being as well. All these dimensions have to operate in harmony. Today spirituality and mental health are highly concerned area for researchers and psychologists because it is very important in every level of profession. Mental health refers to the sense of well being and freedom from depression and mental illness. Mental health indicates harmony between cognitive, affective and behaviour domains-a balance between thinking, feeling and action. Psychosocial rehabilitation reviews the spirituality tends to define it as a broad personal belief system rather than an organized religious system of worship. American psychologist Spaniol (2002) discusses this psychosocial definition of spirituality and its positive worldview. It is a "relationship with someone or something beyond ourselves; someone or something that sustains and comforts us, guiding our decision making, forgiving our imperfections, and celebrating our journey through life".

Australian occupational therapists Bassett et al. (2008) reviewed the definitions of spirituality and defined spirituality as "the individualized need to understand the purpose of life and underpins the meaning of everyday activities. It is the essence of the person and their inner motivator. The concept of spirituality is, therefore, an important consideration in recovery from mental illness". Murphy (1997) supports the views of these definitions with her personal experience of mental illness. She contends that her spiritual beliefs combined with medication provided clarity of thought that grounded her and supported her recovery from mental illness. Such interpretations suggest that spirituality is a positive coping strategy that supports people experiencing personal challenges.

\section{Theoretical Background}

Psychology is always evolving. Although the field has moved into a more eclectic mix of its founders' theories with newer constructs instead of the single recipe approach, it has also moved away from one concept that the entire field of Psychology was built on: spirituality. Most people associate the mind, not spirituality with Psychology. However, the original definition of the word Psychology is "study of the soul" (Morgan, 1994). This makes it difficult to argue with the original purpose of Psychology. One of the most respected founding fathers of Psychology, Carl Jung, incorporated spiritual concepts into his famous theories and writings (Morgan, 1994). However, throughout history the recognition of the spiritual aspect of Psychology has dwindled, even as it has become more common in the mainstream. Increasingly, organizations classify spirituality by offering traditionally trained counselors or Christian counselors, possibly leaving little room for the vast area in between the two, and leaving a difficult choice for those who do not completely identify with either of those two categories or identify with both.

Evidence for religion playing a role in human life dates back 500000 years ago when ritual treatment of skulls took place during China's Paleolithic period (Smart \& Denny, 2007). Why has religion endured over this vast span of human history? What purpose has it served and does it continue to serve? It argued that religion is a powerful coping behavior that enables people to make sense of suffering, provides control over the overwhelming forces of nature (both internal and external), and promotes social rules that facilitate communal living, cooperation, and mutual support.

Until recent times, spirituality and mental health care were closely aligned (Koenig et al. 2001). Many of the first mental hospitals were located in monasteries and run by priests. With some exceptions, these religious 
institutions often treated patients with far more concern than state-run facilities prior to $19^{\text {th }}$ century mental health reforms (reforms often led by religious people such as Dorothea Dix \& William Tuke). In fact, the first form of psychiatric care in the United States was moral treatment, which involved the compassionate and humane treatment of people with mental illness a revolutionary notion at a time when patients were often put on display in despicable conditions in the back wards of hospitals or prisons (Taubes, 1998). Religion was believed to have a positive, civilizing influence on these patients, who might be rewarded for good conduct by allowing them to attend chapel services. However, in the late 19th century, the famous neurologist Jean Charcot and his star pupil, Sigmund Freud, began to associate religion with hysteria and neurosis. This created a deep divide that would separate religion from mental health care for the next century (Freud, 1962; Ellis, 1988; Watters, 1992; Jones, 2007).

Larson et al. (1992) found the majority of studies between 1978 and 1989 classified religiosity in terms of affiliation. Even with this narrow of a definition, many of the studies showed a positive relationship between mental health and religion. $90 \%$ of the population believes in God, but only about $42 \%$ attend worship services weekly (Marwick, 1995). Some of those people may go to the woods, meditate, serve their community, pray at home, or practice spirituality in other ways. For decades, behavioral science research has reported that religious/spiritual (R/S) variables are modestly and positively associated with prevention of illness, reduced mental disorder, increased treatment effectiveness, and improved ability to cope with and recover from major medical disabilities and serious addiction (Larson, 1993; Larson, Swyers, \& McCullough, 1997).

Today, attitudes toward religion in psychiatry have begun to change. The American College of Graduate Medical Education now states in its Special Requirements for Residency Training for Psychiatry (1994) that all programs must provide training on religious or spiritual factors that influence psychological development. Part of this change has been driven by scientific research during the past 2 decades that suggests religious influences need not always be pathological, but can actually represent resources for health and well-being.

\subsection{Significance of the study}

The significance of this study is to find out the impact of spirituality on mental health among normal and chronic diseases group. This study will help academician, researchers and psychologists to confirm that there is positive association between spirituality and mental health. This study will consider two groups' i.e. normal healthy individuals and chronic diseases group will support the above mentioned issue that high spirituality is precondition for good mental health.

\section{Literature review}

Swinton (2001) argues that spirituality is an intra, inter and trans-personal experience that is shaped and directed by the experiences of individuals and of the communities in which they live out their lives. Thus, it's interaction with a person's mental and physical health is likely to be complex, interactive and dynamic. Margetic et al. (2005) revealed that for over a century, the benefits of spiritual activity for physical health have been recognized and documented. At the most rudimentary level, some kinds of spiritual activity seem to make you live longer. A comparative study by Koss (1987) shows mental health patients had more confidence in a spiritual healer rather than a traditional counselor. They were also more satisfied with their recovery.

Consumers have identified spirituality as an essential feature of recovery as it "is an important source of hope and meaning when redefining one's life after the catastrophic event that severe mental illness may be for an individual". Schrank and Slade (2007) reviewed the key components of recovery identified by people with a mental illness. They found spirituality, hope, meaning and purpose were important. These factors enabled consumers to withstand the suffering they had experienced as a result of their illness. Bassett et al. (2008) also support their findings and reviewed the literature addressing the relationship between spirituality, hope and recovery from mental illness. Most of the researchers found an evidence spirituality provided purpose and 
meaning which improved consumer's motivation to recover from their illness.

American social researcher Sullivan (1993) conducted a qualitative study of coping strategies employed by people with a serious mental illness and reported that 19 out of 40 participants (48\%) identified spiritual beliefs as integral to their recovery. The participants believed that spirituality provided meaning to the unpredictability of their illness. Their congregation, prayers and a belief in a benevolent God combined to provide social support. Levin and Schiller (1987) after reviewed nearly 250 research studies examined the relationship between spiritual commitment and stroke, cancer, cardiovascular disease, colitis, hypertension, enteritis, general health status and mortality. They reported consistently positive correlations between spiritual commitment and these health variables. The relationship between blood pressure and spiritual commitment has been studied extensively. Larson et al. (1989) revealed that men who believed in spiritual commitment that was important to them and who regularly attended spiritual services had significantly lower diastolic blood pressures than men who were not spiritually committed. Ferraro and Jensen (1991) reported that frequency of prayer and spiritual service attendance was significantly associated with health status independent of age.

A strong body of evidence appears to reveal a positive relationship between spiritual commitment and health status but there is not a direct cause and effect relationship. Most empirical research has focused on the relationships of spiritual coping, spiritual beliefs, and spiritual involvement and health outcomes in mental health, hypertension, depression, and anxiety. Matthews et al. (1998) reviewed the relationships of religious factors that included religious attendance and mental health status. They concluded that there was strong support for religious commitment and positive medical outcomes following serious illnesses e.g. heart disease, cancer. Pargament et al. (1998) supporting the same by using a spiritual well being scale found there was a relationship between positive and negative patterns of religious coping in young and elderly age groups. They measured three diverse sample groups experiencing stressful life events. The first sample represented Oklahoma City residents who were evaluated for religious coping after the federal building bombing. The second sample involved college students who had experienced a significant negative event, such as a death of a friend or family problems. The third sample group was hospitalized patients over the age of 55 with moderately severe medical illness. Although, the participants were of different ages and diverse life event stressors, a positive pattern of religious coping was found among the three groups. Those participants with positive religious coping patterns had less psychological anxiety and distress. Those individuals with negative religious coping were associated with greater emotional distress, e.g. depression and reported poorer quality of life. Pargament et al. (1990) extended their religious coping research to more clearly identify the kinds of religious beliefs and behaviors that are helpful to individuals as they cope with negative life events like death, illness, divorce and work related problems.

Edward (2002) shows the evidence of spiritual well-being is positively related with self ratings of physical health and vitality. Spiritual health/wellness is positively related with adjustment to dialysis treatment, cancer induced pain, but negatively to hypertension. Various studies in USA indicate that patients and physicians would like to consider spiritual health factors in the medical care and its assessment too. They also indicate a positive correlation between patients' spiritual/religious commitments and health outcomes and would also like physicians to consider these factors in their medical care practice. Subsequently, they suggested spiritual health assessment as a first step of including patients' spirituality in medical care practice.

Australian general practitioners and researchers Benson and Thistlethwaite (2008) evaluated the relationship between spirituality and mental illness. They concluded that spiritual beliefs and practices help to build up resilience - the capacity to learn from positives while experiencing adversity. Their work suggests that it may be important for mental health services to include counselors who specialize in spirituality to assist people to explore and implement spiritual coping strategies (Smark, 2009; Carey \& Smark, 2009). Spirituality can help to relieve suffering not just for people living with a mental illness, but also for their carers. Pastoral care, it can be suggested, has an invaluable contribution to make to recovery from mental illness.

In studying the relationship between spirituality and health it should be noted that this works both ways and 
a person's health will affect their spiritual beliefs. Balboni et al. (2007) explained the same that spiritual beliefs may increase or become more salient to a person after being diagnosed with a potentially life threatening disease such as cancer. Immobility due to ill health can lead to decreased church attendance, but increased private spiritual practices in those who are already very spiritual. Those with more self-reported distress due to their disease, in this case cancer, were found to be more religious, but it was unclear whether this was because those with increased religiosity experienced higher levels of distress, or because those in great pain and discomfort turned to their religious beliefs more than others. Anyone carrying out research into this field must therefore be wary of drawing conclusions from possibly cyclical relationships between these two variables.

Pointing the importance of continued research, Lukoff et al. (1992) noted the importance of spiritual issued in their patients by stating, "the religious and spiritual dimensions of culture are among the most important factors that structure human experience, beliefs, values, behavior and illness patterns". Peteet (1985) raised additional questions regarding the role spirutuality plays in lives of people with a terminal illness. The fact, 32 out of 50 patients expressed religious concerns provides an impetus for health care providers to gain a broader understanding of spirituality as a factors in mental health and psycholgical well-being. Spiritual researches investigated the possible relationships of pain, health and functional recovery. In each study, older adults have a high degree of spirituality on various measurement tools, but only one study reported a significant correlation that included a finding of less depression. The investigation of spirituality and health has not been evaluated using consistent measures of spirituality scales and postoperative population groups. Most of the current researches have observed possible religious affiliation, spiritual beliefs and functional status.

All previous studies related to spirituality around the world extract that spirituality is significantly associated with mental health. Therefore, the present study compares the spirituality and mental health among normal healthy individuals and chronic diseases group. Current study directs in following sections: first section deals with introduction, theoretical background and significance of the study, Second section includes the review of literature, objectives and hypotheses, third section discusses the methodology. Fourth section analyzes the data and interpretation. Fifth section concludes the paper and sixth section that is final section of the paper also discuss about the implications of the study.

\subsection{Objectives of the study}

$>\quad$ To ascertain the association between spirituality and mental health.

$>\quad$ To assess and compare spirituality among normal and chronic disease group.

$>\quad$ To assess and compare mental health among normal and chronic disease group.

\subsection{Hypotheses of the study}

> $\mathrm{H}_{1}$ : There will be positive correlation between spirituality and mental health.

$>\mathrm{H}_{2}$ : Normal healthy group would score higher on spirituality than chronic disease group.

$>\mathrm{H}_{3}$ : Normal healthy group would have better mental health than chronic disease group.

\section{Methods}

\subsection{Sample}

The sample comprised of 100 individuals (50 normal healthy individuals, 50 chronic disease group individuals). Already diagnosed patients by the physician were included in chronic disease group. Chronic disease group consists of hypertensive, diabetics and asthmatic patients. The control group was normal healthy 
Sodhi, R. \& Manju

individuals who maintain good health. The age range of sample varies from 35-50 years. The age, sex and socio economic status was controlled. Incidental sampling method was used.

\subsection{Tools}

The following instruments were used for the purpose of data collection in the present study:

Spirituality Assessment Inventory (SAI)

Spirituality Assessment Inventory is given by Todd W. Hall and Keith J. Edwards. This scale measures the spiritual maturity of the individual. SAI consists of two primary dimensions (Quality of relationship with God, and Awareness of God) and five subscales (Awareness, Realistic Acceptance, Disappointment, Grandiosity and instability). A new set of impression management (IM) items were developed and added into scale profile. The reliability for the subscales is Awareness 0.95, Disappointment 0.90, Realistic Acceptance 0.83, Grandiosity 0.73, and Instability 0.84 .

\section{General Health Questionnaire (GHQ)}

GHQ is given by David Goldberg and Paul Williams. The scale Measures Physical and mental health of the individual. We will use the shorter version of GHQ-30. The Split-Half reliability coefficient of GHQ-30 is 0.92 and test-retest reliability is 0.77 . Specificity (\%) is 87.0 and Sensitivity (\%) is 91.4 .

\subsection{Statistical Analysis}

As per the objectives the following statistical tools were used: Pearson Product Moment Correlation and $\mathrm{t}$-test that are calculated with the help of SPSS $\left(16^{\text {th }}\right.$ version $)$.

\section{Results and discussion}

Table 1 presents the correlation between six factors of Spirituality and Mental health and Table 2 represents the t-test for the spirituality and mental health of normal and chronic disease group.

\section{Table 1}

Correlation Matrix $(N=100)$

\begin{tabular}{|c|c|c|c|c|c|c|c|}
\hline Variables & $\mathrm{A}$ & RA & $\mathrm{D}$ & G & I & IM & GHQ \\
\hline A & 1 & & & & & & \\
\hline RA & $\begin{array}{r}-.108 \\
.284\end{array}$ & 1 & & & & & \\
\hline D & $\begin{array}{r}-.175 \\
.082\end{array}$ & $\begin{array}{r}.811^{* * *} \\
.000\end{array}$ & 1 & & & & \\
\hline G & $\begin{array}{r}.407^{* *} \\
.000\end{array}$ & $\begin{array}{r}.295^{* *} \\
.003\end{array}$ & $\begin{array}{c}.246^{*} \\
.013\end{array}$ & 1 & & & \\
\hline I & $\begin{array}{r}.492^{* *} \\
.000\end{array}$ & $\begin{array}{l}.207^{*} \\
.039\end{array}$ & $\begin{array}{r}.274^{* * *} \\
.006\end{array}$ & $\begin{array}{r}.399^{* * *} \\
.000\end{array}$ & 1 & & \\
\hline IM & $\begin{array}{c}.703^{* *} \\
.000\end{array}$ & $\begin{array}{r}-.039 \\
.701\end{array}$ & $\begin{array}{r}. .026 \\
.798\end{array}$ & $\begin{array}{c}.338^{* *} \\
.001\end{array}$ & $\begin{array}{c}.315^{* *} \\
.001\end{array}$ & 1 & \\
\hline GHQ & $\begin{array}{r}-.392^{* * *} \\
.000\end{array}$ & $\begin{array}{r}.548^{* *} \\
.000\end{array}$ & $\begin{array}{r}.510^{* * *} \\
.000\end{array}$ & $\begin{array}{l}.150 \\
.137\end{array}$ & $\begin{array}{r}-.153 \\
.128\end{array}$ & $\begin{array}{r}-.252^{*} \\
.012\end{array}$ & 1 \\
\hline
\end{tabular}

As mentioned first objective of the study to determine the relationship between the scores of spirituality and mental health the Pearson correlation was applied. The awareness subscale was negatively and significantly correlated with mental health $(-.392 * *)$. The point to be noted that higher score on GHQ indicates poor mental health, so the negative correlation between mental health and awareness automatically becomes positive. It 
means that awareness in relationship with God would be moderately related to better mental health. An empirical study of the relationship between religious coping styles and recovery, conducted by American psychologist Yangarber-Hicks (2004) concluded that participants who felt they had a collaborative relationship with God were more actively involved in their recovery than participants with a passive relationship with God.

Table 1 shows the positive correlation between realistic acceptance and mental health $\left(.548^{* *}\right)$ that means there is negative association between them. It means that acceptance of reality leads to poor mental health. The disappointment subscale positively correlated with mental health $(.510 * *)$ also shows the negative association between them. It means who remains disappointed in relationship with god have poor mental health. Koenig (2005) conducted a review of empirical research into the relationship between spirituality and emotional health and concluded that spirituality has a positive effect on coping. It buffers people against stress stemming from mental illness by providing a positive worldview.

The grandiosity and instability subscales were related to mental health but not significantly. Impression management was negatively and significant correlated with mental health $(-.252 *)$ shows the positive association between them. It means that instance spiritual behavior or attitude leads to better mental health. The findings of the study show that the subscale awareness and Impression Management positively and significantly correlated with mental health and realistic acceptance and disappointment was negatively correlated. Hence the hypothesis $\mathrm{H}_{1}$ has been partially accepted.

Table 2

Group statistics

\begin{tabular}{|c|c|c|c|c|c|c|}
\hline \multicolumn{2}{|l|}{ Variables } & $n$ & Mean & $S D$ & $S E$ & $t$-value \\
\hline \multirow[t]{2}{*}{ Awareness } & 1 & 50 & 3.7654 & 0.75254 & 0.10643 & $4.598 * *$ \\
\hline & 2 & 50 & 3.0646 & 0.77151 & 0.10911 & \\
\hline \multirow[t]{2}{*}{ Realistic Acceptance } & 1 & 50 & 2.2748 & 1.39185 & 0.19684 & $-1.971 *$ \\
\hline & 2 & 50 & 2.7312 & 0.86223 & 0.12194 & \\
\hline \multirow[t]{2}{*}{ Disappointment } & 1 & 50 & 2.4626 & 1.08062 & 0.15282 & -1.843 \\
\hline & 2 & 50 & 2.7992 & 0.70696 & 0.09998 & \\
\hline \multirow[t]{2}{*}{ Grandiosity } & 1 & 50 & 2.8638 & 0.83735 & 0.11842 & -.417 \\
\hline & 2 & 50 & 2.9306 & 0.76390 & 0.10803 & \\
\hline \multirow[t]{2}{*}{ Instability } & 1 & 50 & 2.7142 & 0.88101 & 0.12459 & $3.432 * *$ \\
\hline & 2 & 50 & 2.1078 & 0.88566 & 0.12525 & \\
\hline \multirow[t]{2}{*}{ Impression Management } & 1 & 50 & 3.6720 & 0.79052 & 0.11180 & $3.438 * *$ \\
\hline & 2 & 50 & 3.1160 & 0.82619 & 0.11684 & \\
\hline \multirow[t]{2}{*}{ GHQ } & 1 & 50 & 7.3400 & 6.00887 & 0.84978 & $-4.227 * *$ \\
\hline & 2 & 50 & 12.3400 & 5.81907 & 0.82294 & \\
\hline
\end{tabular}

Note: ${ }^{1}$ indicates Normal Healthy Group. ${ }^{2}$ indicates Chronic Disease Group

*Correlation is significant at the 0.05 level. **Correlation is significant at the 0.01 level

As mentioned second objective of the study to determine the significant difference between the mean scores of different subscales of spirituality independent sample t-test applied. The two groups that are normal healthy individuals and chronic disease group were compared with regards to score on spirituality. On the subscale of awareness the mean score of healthy group (3.765) while the mean score of chronic disease group (3.064). The $t$ value (4.598) revealed the significant difference on awareness dimension between two groups. It clearly shows that healthy individuals are more aware in relationship with god than chronic disease group. On the subscale of realistic acceptance the mean score of healthy group (2.274) while the mean score of chronic disease group (2.731). The $t$ value (-1.971) revealed the significant difference on realistic acceptance between two groups. It indicated that realistic acceptance was higher in chronic disease group than normal healthy individuals. On the subscale of instability the mean score of healthy group (2.714) while the mean score of chronic disease group (2.107). The t value (3.432) revealed the significant difference on instability between two groups. It means that healthy individuals are more instable in relationship with God than chronic disease group. Impression management factor shows higher mean score of normal healthy individuals that is (3.672) than chronic disease 
group (3.116). The t value (3.438) which indicated the significant difference between these two groups. It shows that normal healthy individuals' shows higher instance religious behavior than disease group.

As mentioned third objective of the study to determine the significant difference between the mean scores of mental health and to compare the two groups with regards to score on mental health independent sample t-test was calculated. On GHQ the mean score of normal healthy individuals (7.340) and chronic disease group (12.340) and the $t$ value (-4.227). This shows significant difference between normal healthy individuals and chronic disease group. Higher score on GHQ indicates poor mental health and then normal group shows better mental health in comparison to disease group.

Joseph and Rao (1999) carried out the study of individuals in Andhra Pradesh, India, uses the WHO questionnaire on quality of life, measuring six domains: physical, psychological, level of independence, social relationships, spiritual, and environmental. The mean QOL score of the test group was significantly lower than that of the control group for all domains except the spiritual domain. Fryback and Reinert (1999) suggested that spirituality is an essential component to feelings of health and well-being. Many of the subjects viewed spirituality as a bridge between hopelessness and meaningfulness in life. Those who had found meaning in their disease thought they had a better quality of life now than they had before the diagnosis. Thus our results are confirmatory with the above mentioned findings. Hence the hypothesis $\mathrm{H}_{2}$ and $\mathrm{H}_{3}$ has been accepted.

\section{Conclusion}

From the above discussion it can be inferred that various factors of spirituality significantly associated with positive mental health. Thus individuals with high level of spirituality possess good mental health. So, one can enhance one's positive health by improving spiritual beliefs and positive attitude towards life.

\subsection{Implications of the study}

Spiritual beliefs and practices can be seen important resources for coping with illness and contribute to mental pathology in some cases. Psychiatrists should be aware of patients' religious and spiritual beliefs and seek to understand what function they serve. Beyond the contribution spirituality and humor may have to psychological well-being, there may also be implications for positive physical effects, Psychological well-being is important to all individuals and this becomes increasingly important for those with mental illnesses. Because the purpose of this study is to explore the interrelationships among spirituality, psychological well being and mental health, a positive correlation may encourage further research investigating the link between spirituality and mental health. A beneficial link between spirituality and psychological well-being may encourage those diagnosed as chronic diseases patients to explore the spiritual aspects of their lives. That exploration may have positive consequences for their psychological well-being. This, in turn, could contribute to an increase in their overall quality of life.

Health service users are increasingly going outside traditional clinic settings to receive services from practitioners who incorporate spirituality. If it were clearly shown that clients demand spiritually inclusive counseling, academician could expand their programs to address this area more adequately. Furthermore, therapists who were trained in this area would have a more holistic approach, an advantage over those who were not, and client satisfaction outcomes could increase. The demand for therapists may greatly increase if clients who generally must seek services through their church or alternative practitioners can access those services through a professional counselor. We are coming into more holistic medical care. Mental health services must also pay attention to the research and remain current in theory and practice. This study is an important step that clearly identifies what one diverse sample of mental health client's desire of their counselors pertaining to spirituality.

Transpersonal psychology encourages the exploration of all things spiritual. This research explored a positive association between spirituality and psychological well-being, and focused on the relationship between 
Spiritually and mental health among normal and chronic disease group

the qualities of spirituality and mental health among normal and chronic diseases group. Findings of this study will contribute to understand the relationships between the mind and body. Finally, it can be said with exploring the relationship between spirituality and mental health will contribute to the study of transpersonal psychology.

\section{References:}

Accreditation Council on Graduate Medical Education. (1994). Special requirements for residency training in psychiatry. Chicago, IL: ACGME.

Balboni, T. A., Vanderwerker, L. C., Block, S. D., Paulk, M. E., Lathan, C. S., Peteet, J. R., \& Prigerson, H. G. (2007). Religiousness and spiritual support among advanced cancer patients and associations with end-of-life treatment preferences and quality of life. Journal of Clinical Oncology, 25(5), 555-560. $<$ http://dx.doi.org/10.1200/JCO.2006.07.9046>

Bassett, H., Lloyd, C., \& Tse, S. (2008). Approaching in the right spirit: Spirituality and hope in recovery from mental health problems. International Journal of Therapy and Rehabilitation, 15(6), 254-259.

Benson, J., \& Thistlethwaite, J. (2008). Mental health across cultures: A practical guide for health professionals. Sydney: Radcliffe Publishing.

Carey, L. B., \& Smark, T. (2009). Book review: Mental health across cultures: A practical guide for health professionals by J. Benson \& J. Thistlethwaite [2009, Radcliff, Oxon], Australian Journal of Primary Health, Vol. 10 [In press].

Edward, H. (2002). Psychological testing at work. McGraw Hill Series.

Ellis, A. (1988). Is religiosity pathological? Free Inquiry, 18, 27-32.

Ferraro, K. F., \& Albrecht-Jensen, C.M. (1991). Does religion influence adult health? Journal for the Scientific Study of Religion, 30, 193-202. <http://dx.doi.org/10.2307/1387213>

Freud, S. (1962). Future of an illusion. In: J. Strachey (Ed. and Trans.). Standard edition of the complete psychological works of Sigmund Freud. London (GB): Hogarth Press.

Fryback, P. B., \& Reinert, B. R. (1999). Spirituality and people with potentially fatal diagnoses. Nursing Forum, 34(1), 13-22. <http://dx.doi.org/10.1111/j.1744-6198.1999.tb00231.x >

Goldberg, D., \& Williams, P. (1988). Manual for general health questionnaire. Basingstoke, Hampshire: The Basingstoke Press Limited.

Hall, T. W., \& Edwards, K. J. (2002). Manual for spiritual assessment inventory. Journal of the scientific study of Religion, 41(2), 341-357. <http://dx.doi.org/10.1111/1468-5906.00121>

Jones, H. E. (2007). Religion: the etiology of mental illness. Mental Health Education.

Joseph, G. A., \& Rao, P. S. (1999). Impact of leprosy on the quality of life. Bulletin of the World Health Organization, 77(6), 515-7.

Koenig, H. G. (2005). Faith and mental health: Religious resources for healing. Philadelphia: Templeton Foundation Press.

Koenig, H. G., McCullough, M. E., \& Larson, D. B. (2001). A history of religion, science and medicine. In: H. G. Koenig, M. E. McCullough, \& D. B. Larson (Eds.). Handbook of religion and health (pp.24-49). New York, NY: Oxford University Press. <http://dx.doi.org/10.1093/acprof:oso/9780195118667.003.0003>

Koss, J. (1987). Expectations and outcomes for patients given mental health care or spiritist healing in Puerto Rico. American Journal of Psychiatry, 144, 56-61.

Larson, D. B., Koenig, H. G., Kaplan, B. H., Greenberg, R. S., Logue, E., \& Tyroler, H. A. (1989). The impact of religion on men's blood pressures. Journal of Religion and Health, 28, 265-278. $<\underline{\text { http://dx.doi.org/10.1007/BF00986065> }}$

Larson, D. B., Sherrill, K. A., Lyons, J. S., Craigies, F. C., Thielman, S. B., Greenwold, M. A., \& Larson, S. S. (1992). Associations between dimensions of religious commitment and mental health reported in the American Journal of Psychiatry and Archives of General Psychiatry: 1978-1989. American Journal of Psychiatry, 149, 557-559.

Larson, D. (1993). The faith factor: An annotated bibliography of systemic reviews and clinical research on spiritual subjects: Vol. 2. Washington, DC: National Institute for Healthcare Research. 
Larson, D., Swyers, J., \& McCullough, M. E. (1997). Scientific research on spirituality and health: A consensus report. Washington, DC: National Institute for Healthcare Research.

Levin, J. S., \& Schiller, P. L. (1987). Is there a religious factor in health? Journal of Religion and Health, 26, 9-36. <http://dx.doi.org/10.1007/BF01533291>

Lukoff, D., Lu, F., \& Turner, R. (1992). Toward a more culturally sensitive DSM-IV: Psycho religious and spiritual problems. Journal of Nervous and Mental Disease, 180(11), 673-682. <http://dx.doi.org/10.1097/00005053-199211000-00001>

Marwick, C. (1995). Should physicians prescribe prayer for health? Spiritual aspects of well-being considered. Journal of the American Medical Association, 273(20), 1561-1562. <http://dx.doi.org/10.1001/jama.1995.03520440013005>

Matthews, D. A., McCullough, M. E., Larson, D. B., Koenig, H. G., Swyers, A., \& Milano, M. G. (1998). Religious commitment and health status. Archives of Family Medicine, 7, 118-124. $<\underline{\text { http://dx.doi.org/10.1001/archfami.7.2.118> }}$

Morgan, P. P. (1994). Spirituality slowing gaining recognition among North American Psychiatrists. Canadian Medical Association Journal, 150(4), 582-585.

Murphy, M.A. (1997). First person account: Meaning of psychoses. Schizophrenia Bulletin, 23(3), 541-543. $<$ http://dx.doi.org/10.1093/schbul/23.3.541>

Paragment, K. I., Ensing, D. S., Falgout, K., Olsen, H., Reilly, B., Van Haitsma, K., \& Warren, R. (1990). God help me (1): Religious coping efforts as predictors of the outcomes to significant negative life events. American Journal of Community Psychiatry, 18, 793-824. <http://dx.doi.org/10.1007/BF00938065>

Pargament, K. I., Smith, B. W., Koenig, H. G., \& Perez, I. (1998). Patterns of positive and negative religious coping with major life stressors. Journal for the Scientific Study of Religion, 37, 710-724. $<$ http://dx.doi.org/10.2307/1388152>

Peteet, J. (1985). Religious issues presented by cancer patients seen in psychiatric consultation. Journal of psychosocial Oncology, 3(1), 53-66. <http://dx.doi.org/10.1300/J077v03n01_04>

Schrank, B., \& Slade, M. (2007). Recovery in psychiatry. Psychiatric Bulletin, 31, 321-325. $<$ http://dx.doi.org/10.1192/pb.bp.106.013425>

Smark, T. (2009). Resilience and spirituality-A chapter review: Mental health across cultures: A practical guide for primary care' by J. Benson and J. Thistlethwaite (2008; Sydney: Radcliffe), Australian Journal of Pastoral Care and Health, 3(1), June.

Smart, N., \& Denny, F. W. (2007). Atlas of the world's religions. In: N. Smart \& F. W. Denny (Eds.), Atlas of the world (p. 26). New York, NY: Oxford University Press.

Spaniol, L. (2002). Spirituality and connectedness. Psychiatric Rehabilitation Journal, 25(4), 321-322.

Sullivan, W. P. (1993). It helps me to be a whole person: The role of spirituality among the mentally challenged. Psychosocial Rehabilitation Journal, 16(3), 125-134.

Swinton, J. (2001). Spirituality and mental health care: Rediscovering a forgotten dimension. London, Jessica Kinglsey Publishers.

Taubes, T. (1998). Healthy avenues of the mind: psychological theory building and the influence of religion during the era of moral treatment. American Journal of Psychiatry, 155, 1001-1008.

ukst-Margetic, B., \& Margetic, B. (2005). Religiosity and health outcomes: Review of literature. Collegium Antropologicum, 29 (1), 365-371.

Watters, W. (1992). Deadly doctrine: Health, illness, and Christian God-talk. Buffalo, NY: Prometheus Books. Yangarber-Hicks, N. (2004). Religious coping styles and recovery from serious mental illnesses. Journal of Psychology and Theology, 32(4), 305-317. 